los hispanoamericanos residentes en la isla, las revistas literarias y los periódicos escritos en español (en los que se publican bastantes artículos de escritores españoles), las compañías teatrales procedentes de la Península y los colegios o instituciones culturales de las islas.

ReseñAs.-U. Leo, sobre: Kurt Wais, Zwei Dichter Südamerikas. Gabriela Mistral, Rómulo Gallegos (Berlín, 1955), pp. $263-278$ (trabajo superficial "en forma y método", pero útil como obra de divulgación).-E. v. Richthofen, sobre: Alfonso Martínez de Toledo, Arcipreste de Talavera, ed. M. Penna (Torino, 1955), y sobre: J. González Muela, El infinitivo en "El Corbacho" del Arcipreste de Talavera (Granada, 1954), pp. 279-281 (breve descripción de la edición y del estudio).-R. O[roz], sobre: El Poema de Alfonso XI, ed. Yo ten Cate (Madrid, 1956), pp. 283-285 (aunque no reúne "las condiciones ideales" de una edición crítica, el trabajo es muy meritorio).- R. O[roz], sobre: H. Toscano Mateus, El español en el Ecuador (Madrid, 1953), pp. 286 -288 ("estudio de gran utilidad para la dialectología hispanoamericana", al que sería conveniente agregar una exposición completa del sistema fonológico quechua).-R. O [roz], sobre: B. Vigón, Vocabulario dialectológico del concejo de Colunga, ed. A. M. Vigón Sánchez (Madrid, 1955), pp. 289-29o (es todavía una importante obra de consulta).-A. Rabanales, sobre: G. Devoto, Los fundamentos de la historia lingüistica (Buenos Aires, 1955), pp. 291-297 (índice detallado de la obra).-L. Contreras, sobre: E. Buyssens, Les langages et le discours. Essai de linguistique fonctionnelle dans le cadre de la sémiologie (Bruxelles, 1943), pp. 299-306 (claro resumen de la doctrina). - I. Césped, sobre: J. J. Arrom, El teatro de Hispanoamérica en la época colonial (La Habana, 1956), pp. 307-313 (obra perfectamente sistematizada, de la que ofrece una detallada relación).-I. Césped, sobre: Don Juan Manuel, Obras, ed. J. M. Castro y M. de Riquer (Barcelona, 1955), pp. 314316 (resumen del prólogo).-E. García, sobre: L. Spitzer, Lingüistica e Historia literaria (Madrid, 1955), pp. 317-320 (comenta las cuestiones metodológicas planteadas en el primer ensayo de los seis que constituyen el libro).-E. Camus, sobre: G. Correa, La poesia mítica de Federico Garcia Lorca (Eugene, Or., 1957), pp. 321-336 (abundantes objeciones de fondo a este trabajo que, no obstante, "representa un paso importante en la interpretación de la poesía" lorquiana).-J. M. L. B.

\title{
CUADERNOS AMERICANOS
}

\section{Año 6 (1947).}

Núm. 1: A. Jiménez, "Hasta siempre", pp. 143-150: Sobre Keyserling, sus viajes a España y sus juicios acerca de la cultura hispánica.-G. DE Torre, "Prisma de Lope de Vega: lo clásico, lo español, lo universal", pp. 179-19o: Conceptos de clasicismo y universalidad con referencia a la obra de Lope, tan olvidada (al igual que otras obras hispánicas) en los panoramas de literatura universal y en las colecciones de "cien obras maestras".

Núm. 2: R. Altamira, "La mujer española a través de la historia", pp. 175203: "Cuadro panorámico, desde la Edad Media hasta la República española; se refiere a la situación jurídica de la mujer, la literatura en pro y en contra de ella, la mujer en la educación, etc.-P. SALINAs, "Significación del esperpento, o Valle-Inclán, hijo pródigo del 98”, pp. 218-244: Como las Humoradas de Campoamor, las Rimas de Bécquer, las Glosas de d'Ors y las Greguerias de Gómez de la Serna, los esperpentos de Valle nacen de un afán personal de originalidad; sin embargo, "la significación del esperpento está en haber traído el modernismo... al servicio del Noventa y ocho".-R. Brughetti, "Pedro B. Palacios (Almafuerte)", pp. 254-265: Valoración y elogio del discutido poeta argentino. 
Núm. 3: A. Uslar Pietri, “Andrés Bello, el desterrado", pp. 153-165: Trabajos y días de Bello en Londres y en Santiago de Chile.

Núm. 4: F. M. Torner, "Arte puro y estética impura”, pp. 118-134: El pensamiento estético de Ortega y Gasset "camina a bandazos contradictorios, con arbitrariedad absolutamente irresponsable"; La deshumanización del arte no es el análisis objetivo que pretende ser, sino exposición de la "personal ideología política" de Ortega. [El punto de partida de Torner es el ensayo de J. Gaos, "La profecía en Ortega", publicado en esta misma revista, año 5, núms. 5 y 6 , y año 6, núm. 1, trabajo que no hemos comentado por tener un enfoque estrictamente filosófico].-J. L. Martínez, "Siete novelas mexicanas de hoy", pp. 267-275: Somero análisis de sendas novelas de Francisco Rojas González, Miguel N. Lira, Agustín Yáñez, Jesús Goytortúa, Luis Spota, Diego Cañedo y Rafael Bernal.

Núm. 5: R. Iglesia, "El reaccionarismo de la generación del 98", pp. 9299: Contra lo que generalmente se piensa, sostiene el autor que, lejos de ser una generación revolucionaria, la del 98 se caracteriza más bien por el reaccionarismo de sus miembros más importantes, con la sabida excepción de Antonio Machado.-E. Nicol, "Conciencia de España", pp. 100-122: La "singularidad más radical" de la España moderna consiste en "su esfuerzo por encontrarse a sí misma", por interrogarse y hacer balance de sus valores; ahora estamos "en situación de hacer balance del balance", sobre todo con la ayuda de la excelente antología de A. del Río y M. J. Benardete, El concepto contemporáneo de España (Buenos Aires, 1946), donde se recogen páginas -que Nicol comenta -de Cajal, Cosío, Ganivet, Maragall, Menéndez Pidal, Azaña, d’Ors, Ortega, Madariaga, Castro y, en general, de los hombres del 98.-F. Alegría, “Orígenes del romanticismo en Chile", pp. 173-193: Más de un siglo después, las encontradas posiciones de Sarmiento y Lastarria por un lado y Bello por otro, suscitan ensayos como éste, en el que el autor se esfuerza por poner objetivamente a cada uno en su lugar.-F. AyalA, "Nota sobre la creación del Quijote", pp. 194-206: El Quijote se desarrolla en tres diferentes planos: el realista, el idealista y el trascendental. Oscurecido por el primero y el último, el plano idealista está más alejado de la percepción del hombre actual; se halla representado en las historias de Marcela y Grisóstomo, Cardenio y Lucinda, "El curioso impertinente", etc.; tiempo es de arrumbar "la vulgar idea que considera artificiosamente injertas" en el Quijote esas y otras historias.-R. LidA, "Cultura de Hispanoamérica", pp. 207-212: Comenta la Historia de la cultura en la América hispánica de Pedro Henríquez Ureña, quien "en pocos trabajos suyos se nos muestra tan pleno como en este libro póstumo".-L. A. SÁnchez, "La novela: signo humano, espejo social", pp. 231-244: Interesante recopilación de nociones y juicios de diferentes autores (de Menéndez Pelayo a Roger Caillois) sobre ese género.-J. A. Portuondo, "Lino Novás Calvo y el cuento hispanoamericano", pp. 245-263: Después de un breve repaso de las tendencias de ese género en Hispanoamérica, de Horacio Quiroga a Borges, estudia la obra del escritor cubano, a quien decididamente considera "el primero entre los cuentistas de lengua española”.

Núm. 6: A. Fernández Suárez, "Sentido y heroísmo del mito de Dulcinea", pp. 40-61: Buen ensayo interpretativo. Como cuando no quiso probar por segunda vez la celada, don Quijote "sabe" que Dulcinea es un mito de su propia creación, pues "es un realista que trata de anegar su realismo para darse una razón de vivir".-A. REyes, "De un autor censurado en el Quijote (Torquemada)", pp. 189-224: Análisis de los Coloquios satíricos y del Jardín de flores curiosas de Antonio de Torquemada, autor del Olivante de Laura condenado a la hoguera en el Quijote. Cervantes aprovechó muchas de las fantasías del Jardin y las incorporó en varios lugares del Persiles. 
Año 7 (1948).

Núm. 1: L. Nicolau d'Olwer, “América en la obra de Cervantes”, pp. 162-184: Referencias a cosas y lugares de América en las obras de Cervantes.J. Camp, "La casa del caballero loco", pp. 218-229: Nuevo descubrimiento y nueva defensa de las virtudes de Sancho Panza " "icómo admiro a este sencillo y angélico Sancho....!", etc.).-R. IвÁñEz, "Americanismo y modernismo”, pp. 230-252: En el modernismo "caben y se aparean representativamente Darío y Rodó, como señales solidarias de la unidad cultural de América".-G. DE Torre, "El existencialismo en la literatura", pp. 253-272, y núm. 2, pp. 223-234: Estudia sobre todo a Sartre, y considera, entre otros aspectos, los "precedentes españoles": Unamuno, A. Machado y sobre todo Ortega y Gasset, quien se anticipó a muchos de los "hallazgos" filosóficos de Heidegger.

Núm. 2: R. LidA, "Vossler y la historia de la lengua", pp. 113-127: Para Vossler, "trazar la historia de un idioma es trazar la historia de sus hablantes, es uno de sus aspectos", la historia "de su intuir y expresar en palabras" (concepción a la vez histórica y estilística). Enemigo de las tendencias naturalistas, deterministas y mecanicistas, Vossler insiste en la vinculación de cultura y lengua, y ve en el espíritu humano, con su constante actividad creadora, "el único motor eficaz de las transformaciones históricas de la lengua".

Núm. 3: A. IduARTe, "Rómulo Gallegos en España", pp. 20-33: Recuerdos, anécdotas y caracterización espiritual del gran novelista, a quien conoció Iduarte en Madrid, en 1933.-D. Cúneo, "Unamuno y el socialismo", pp. 103-116: Unamuno fue un clarividente y bien informado socialista, como se demuestra por el análisis de muchos de sus escritos; sin embargo, "rehusó siempre suponerse adherido a partido alguno"; además, según él, el factor económico no explica a todo el hombre, sino sólo uno de sus aspectos. - J. A. Portuondo, “"Períodos» y "generaciones» en la historiografía literaria hispanoamericana", pp. 231-252: Critica los equivocados conceptos con que, hasta antes de Henríquez Ureña, se intentó establecer los "períodos" y "generaciones"; y, partiendo de Henríquez Ureña, propone nuevos esquemas cronológicos.-F. GINer DE LOS Ríos, "Historia y novela del Ecuador", pp. 286-292: Nota sobre La novela ecuatoriana de Ángel F. Rojas, libro que, rebasando lo anunciado en el título, ofrece "un espléndido panorama cultural, social y político del Ecuador".

Núm. 4: E. Nicol, "Libertad y comunidad", pp. 79-104: Estudia el pensamiento político de Francisco Suárez y subraya su modernidad; pone de relieve en particular el hecho de que el Tratado de las leyes "contiene todas las ideas principales de política que se encuentran en Locke, y que luego reaparecen... en la Declaración de los Derechos del Hombre" (1789).-P. Вosch Gimpera, "Cervantes y un momento crucial de la historia de España”, pp. 152-161: La vida atribulada de Cervantes, vista contra el negro trasfondo histórico de la España de los Felipes.-V. Llorens Castillo, "El retorno del desterrado", pp. 216-233: El destierro y sus temas -esperanza, nostalgia, la imagen de la muerte, actitud de "perdón y dignidad"- vistos a través de la poesía española, desde el Cantar de mio Cid hasta la emigración republicana (Alberti, Moreno Villa, Cernuda, Prados, Rejano), pasando por Enríquez Gómez, Meléndez Valdés, Pérez del Camino, Rivas, Espronceda, Alcalá Galiano, Víctor Balaguer y Unamuno.-J. López Morillas, "Unamuno y sus criaturas: Antolín S. Paparrigópulos", pp. 234-249: Tras algunas consideraciones sobre la técnica novelística de Unamuno, relaciona el cap. 23 de Niebla (donde aparece, como digresión o entremés, el episodio de Paparrigópulos) con ciertas ideas expuestas por Unamuno en ensayos anteriores, en particular su aborrecimiento de la erudición fría, pedantesca, alejada de la vida.

Núm. 5: E. Martínez Estrada, "Imagen de Martín Fierro", pp. 99-125: Fragmento del magnífico libro Muerte y transfiguración de "Martin Fierro" (Mé- 
xico, 1948).-F. Schultz de Mantovani, "La infancia mágica y real de Sarmiento y José Marti”, pp. 188-208: En muchos rasgos de la infancia de ambos escritores se ven ya (dice la autora) su carácter y su decisión futuros.-E. RodRíguez Monegal, "Imagen documental de José Enrique Rodó", pp. 214-226: Pondera el valor de los estudios de Roberto Ibáñez sobre los "originales y documentos" de Rodó, los cuales arrojan luces nuevas sobre el gran uruguayo.E. G. DA CAL, "Don Segundo Sombra: Teoría y símbolo del gaucho", pp. 245259: Señala, entre otras cosas, los valores estilísticos de la novela de Güiraldes y el acierto de éste al instalarse dentro del héroe por medio de la forma autobiográfica.

Núm. 6: P. Frank de Andrea, "Saavedra Fajardo y su visión del gobernante", pp. 170-189: Examina las ideas políticas de este autor a través de sus obras; señala su coincidencia con algunos principios políticos de aplicación posterior.-J. L. Martínez, "Situación de la literatura mexicana contemporánea", pp. 229-251: Agudo y pesimista análisis de la situación de las letras mexicanas. -F. Giner DE Los Ríos, "Invitación a la poesía de Alfonso Reyes", pp. 252265: Se adentra en la vasta y singular obra poética de Reyes, cuyo "equilibrio le hace parecer y ser clásico en medio de los atrevimientos más inusitados".L. ZEA, "La filosofía de Andrés Bello", pp. 137-140: Nota sobre la Filosofía del entendimiento de Bello, quien "también en el campo de la filosofía es un espíritu creador".-A. M.

\section{LETTERATURE MODERNE. Università Bocconi, Milano.}

Tomo 1 (1950).

F. Flora, "Unanesimo", pp. 19-29. - Reflexiones en torno al humanismo como época histórica y como actitud permanente del espíritu.

C. Cordí, "I fratelli Folengo e la Spagna", pp. 66-76.-Resume los datos que se conocen sobre la influencia de Teófilo en España (Juan de Vergara, Lope de Vega, Barahona de Soto, Villaviciosa), e invita a los hispanistas a indagar la posible influencia de Giambattista en la literatura religiosa de tendencia "renovadora" y erasmizante.

M. Praz, "Sulla storia letteraria", pp. 198-206.-Es el mismo artículo que se publicó en $C L, 2$ (1950), 97-106 (cf. NRFH, 12, 461).

\section{Tomo 2 (1951).}

A. Gasparetti, "Sulla fonte italiana della Patraña VI di Juan de Timoneda", pp. 7o-81.-El núcleo de este cuento (los dineros perdidos) está en Pedro Alfonso, en Sánchez de Vercial y en los italianos Doni y Giraldi Cinthio; pero la patraña de Timoneda incluye además el episodio del asno y el de la mujer preñada, los cuales figuran, junto con el de los dineros, en sendas novelle de Sacchetti $(† 1410)$ y Sercambi $(† 1424)$; aunque se publicaron, respectivamente, en el siglo xvin y en el xix, Timoneda pudo conocerlas de oídas, -sobre todo la de Sacchetti, cuyo tono es más "folklórico".

G. MArone, "Martin Fierro, poema della pampa argentina”, pp. 149-163.Artículo de divulgación: el gaucho como tipo social, la literatura gauchesca, el poema de Hernández y sus valores, etc. [¿Por qué dice (p. 161) que los octosílabos del Martin Fierro son "irregulares"?].

G. M. Bertini, "Drammatica comparata ispano-italiana", pp. 418-437.-Tomando pie en las tesis de Américo Castro sobre las diferencias de espíritu nacional, contrasta el "hábito de severidad, de captación de valores trascendentales" que tenían los españoles del Siglo de Oro, con el espíritu "escéptico y burlón" de los italianos. Así, Giacinto A. Cicognini, al "traducir" al italiano 